\title{
SARCOMA HISTIOCÍTICO COM MÚLTIPLAS LOCALIZAÇÕES EM UM CÃO
}

Lígia Assunção Oliveira ${ }^{1}$; Talita Cristina Modesto ${ }^{1}$; Marco Aurélio da Cunha Dias ${ }^{1}$; Alessandra Aparecida Medeiros-Ronchi²; Márcio de Barros Bandarra².

1- Médico Veterinário Residente em Patologia Animal, Universidade Federal de Uberlândia, Uberlândia - MG. E-mail: ligiassuncao@hotmail.com

2- Professor doutor em Patologia Animal, Faculdade de Medicina Veterinária, Universidade Federal de Uberlândia, Uberlândia - MG.

Recebido em: 06/04/2018 - Aprovado em: 10/06/2018 - Publicado em: 20/06/2018 DOI: 10.18677/EnciBio_2018A75

\begin{abstract}
RESUMO
As doenças proliferativas histiocíticas são desordens conhecidas no cão e que possuem inúmeras origens, muitas ainda não completamente elucidadas. O complexo sarcoma histiocítico pode ser dividido em três principais tipos: sarcoma histiocítico localizado, sarcoma histiocítico disseminado e sarcoma histiocítico hemofagocítico. O objetivo desse trabalho foi relatar um caso de sarcoma histiocítico disseminado acometendo múltiplas localizações em um Rotweiler. $O$ animal foi atendido pelo Hospital Veterinário da Universidade Federal de Uberlândia (HV-UFU) com a queixa de um aumento de volume em membro posterior esquerdo e presença de uma massa em placa na região de glândulas mamárias torácica caudal à inguinal esquerda. Foi realizada a punção aspirativa por agulha fina da massa e obteve-se o diagnóstico de sarcoma histiocítico. Após dois dias de piora clínica o animal foi eutanasiado e então o Laboratório de Patologia Animal do HV-UFU realizou o exame de necropsia. Ao realizar o exame foi observada linfadenomegalia em linfonodos axilar e inguinal esquerdos, e a presença de uma massa aderida à parede dorsal de cavidade abdominal. Os órgãos alterados foram coletados e após realização de exame histopatológico foi confirmado o diagnóstico de sarcoma histiocítico com metástase para linfonodo axilar e inguinal esquerdos.
\end{abstract}

PALAVRAS-CHAVE: citopatológico, complexo sarcoma histiocítico, neoplasma, metástase.

\section{HISTIOCYTIC SARCOMA WITH MULTIPLE LOCATIONS IN A DOG - CASE REPORT}

\begin{abstract}
The histiocyitic proliferative diseases are known disorders of the dog that have numerous origins, many of which are still not completely elucidated. The histiocytic sarcoma complex can be divided into three main types: localized histiocytic sarcoma, disseminated histiocytic sarcoma and hemophagocytic histiocytic sarcoma. The goal of this study is to report a case of a disseminated histiocytic sarcoma that affects many locations on a Rottweiler. The animal came to the Hospital Veterinário of the Universidade Federal de Uberlândia (HV-UFU) with the complaint of an increase of volume of the left limb and the presence of a mass in plaque at the left caudal
\end{abstract}


abdominal and inguinal mammary glands. A fine needle aspiration was performed and the diagnostic of histiocytic sarcoma was obtained. The animal was euthanized after two days of clinical condition worsening and so the Laboratório de Patologia animal of the HV-UFU performed the necropsy exam. During the examination it was observed lymphadenomegaly of the left axillar and inguinal lymph nodes and the presence of a mass attached to the dorsal wall of the abdominal cavity. The affected organs were collected and after the histopathological examinations the diagnostic of histiocytic sarcoma with left axillar and inguinal lymph node metastasis was confirmed.

KEYWORDS: cytopathologic, histiocytic sarcoma complex, histopathologic, metastasis.

\section{INTRODUÇÃO}

As proliferações histiocíticas caninas são desordens derivadas de variáveis células, mas que apresentam características morfológicas semelhantes. Dentre essas proliferações podemos destacar três classificações principais, que podem ser divididas de acordo com seu comportamento biológico, obtendo assim a histiocitose reativa, histiocitoma cutâneo e o complexo sarcoma histiocítico (HENDRICK, 2017) As células de origem das proliferações histiocíticas no cão ainda não foram completamente elucidadas, porém estudos feitos com marcadores imunohistoquímicos indicaram haver uma relação dessas células com células da linhagem de células dendríticas e macrófagos (MOORE, 2014).

Estudos recentes mostram o complexo sarcoma histiocítico indicando expressão de marcadores celulares que levam a crer que as células dessa neoplasia são provenientes de células dendríticas (TAKADA et al, 2018). Esse sarcoma possui células proliferadas de formato ovoide a reniforme, muitas vezes apresentando células binucleadas e gigantes. Algumas raças apresentam predisposição para o aparecimento da neoplasia, como o Bernese Mountain, Golden Retriver, Flat-Coated Retriever e Rottweiller (HENDRICK, 2017). A predisposição genética dessas raças tem sido estudada, tanto para o melhor entendimento do tumor, quanto para auxiliar no conhecimento dessa neoplasia em humanos (HEDAN et al, 2011; TAKADA et al, 2018).

Três entidades são conhecidas por fazerem parte do complexo sarcoma histiocítico, que são o sarcoma histiocítico localizado, o sarcoma histiocítico disseminado e o sarcoma histiocítico hemofagocítico. Esse último possui uma abordagem clinicopatológica diferente, sendo que estudos mostram sua origem no baço, advindas de macrófagos da polpa vermelha que têm origem na medula óssea (MOORE et al, 2006; HENDRICK, 2017;). O sarcoma histiocítico localizado se difere do disseminado quanto à suas características clínicas. O primeiro se apresenta como um único nódulo em pele, enquanto em sua versão disseminada há metástase do tumor primário de pele para outros órgãos além dos linfonodos regionais (HENDRICK, 2017).

Os sarcomas histiocíticos geralmente possuem como primeira característica clínica perceptível nódulos cutâneos, frequentemente encontrados próximos a articulações de membros, porém podendo aparecer em inúmeras localidades na pele. Podem ser nódulos solitários ou múltiplos, normalmente amarelados ou esbranquiçados, nodulares ou em placas (HENDRICK, 2017). Também, podem ser encontrados nódulos primários do complexo sarcoma histiocítico em baço, linfonodo, pulmão, medula óssea e sistema nervoso central, podendo frequentemente sofrer metástase para fígado, pulmão e linfonodos (MOORE, 2017). 
No aspecto microscópico observa-se frequentemente células mononucleares, com elevado pleomorfismo, distribuídas em forma de manto. Nota-se elevada quantidade de células gigantes multinucleadas, com numerosas figuras de mitose atípicas. As células geralmente são grandes e redondas, podendo ser também observadas células alongadas, semelhantes a células sarcomatosas (HENDRICK, 2017; MOORE, 2017).

Diversos estudos quanto ao tratamento quimioterápico, cirúrgico, ou uma combinação de ambos, são feitos para elucidar o efeito de cada um na sobrevida do animal. A quimioterapia é indicada como um dos tratamentos principais, tanto para o sarcoma histiocítico localizado, metastático ou não, quanto para o disseminado. A quimioterapia pode ser também utilizada após a realização da retirada cirúrgica ou de radioterapia para as neoplasias localizadas, o que indica um aumento na sobrevida do animal (CANNON et al, 2015; MARIANNI et al, 2015).

Devido às inúmeras possibilidades de locais e formas de aparecimento do complexo sarcoma histiocítico, objetivou-se com esse trabalho, relatar um caso de sarcoma histiocítico disseminado em uma Rottweiller, de 09 anos de idade, que apresentou primariamente na clínica, nódulos em região de glândula mamária.

\section{RELATO DE CASO}

Uma cadela da raça Rottweiller, de nove anos de idade foi atendida no Hospital Veterinário da Universidade Federal de Uberlândia, com queixa de edema no membro posterior esquerdo e apatia. Em exame clínico, foi notada uma massa em placa acometendo a região das mamas torácica caudal a inguinal esquerdas. A massa possuía consistência firme, era aderida em pele, distribuída em placa, e media aproximadamente $20 \times 5 \mathrm{~cm}$. Além disso também foi notado um nódulo em mama torácica cranial direita, que possuía consistência firme, não estava aderido, e media aproximadamente $3 \mathrm{~cm}$ de diâmetro.

Foi realizado o exame de punção aspirativa por agulha fina (PAAF) de ambos os tumores, e o material coletado foi corado com a coloração Panótico Rápido® e visualizado em microscopia óptica. $\mathrm{Na}$ análise da amostra coletada da massa em placa, foi observada população celular semelhante a sarcoma histiocítico, sendo esse o diagnóstico sugerido. Já na punção do nódulo em mama torácica cranial direita, foi observada população de células epiteliais, cujo se assemelhou com carcinoma mamário.

O animal obteve piora no quadro clínico e foi indicada a eutanásia dois dias após o primeiro atendimento. Foi então solicitado o exame de necropsia, que foi realizado pelo Laboratório de Patologia Animal da Universidade Federal de Uberlândia. Durante a análise do animal, foi encontrada um aumento de volume em membro pélvico esquerdo, em terço médio de região caudal de coxa, linfonodos axilar e inguinal esquerdos com apresentação macroscópica alterada. Por fim ao retirar os órgãos, notou-se uma massa próxima a vértebras lombares e sacrais, de aproximadamente $13 \times 5 \mathrm{~cm}$, de consistência macia, aspecto multilobulado, e coloração esbranquiçada. Fragmentos da massa cutânea em região de mamas e dos materiais descritos acima foram então coletadas para análise histopatológicas, fixadas em formol a $10 \%$, cortadas, incluídas em parafina, seccionadas em $5 \mu \mathrm{m}$ e por fim coradas em Hematoxilina e Eosina (H.E.).

\section{RESULTADOS E DISCUSSÃO}

Foi realizado um exame de PAAF do nódulo e massa em placa localizadas na mama pelo Laboratório de Patologia Animal da UFU. De acordo com a localização, 
as características macroscópicas e o histórico do animal, a primeira suspeita clínica foi carcinoma mamário (GOLDSMICHT et al, 2017). Na análise microscópica do aspirado da massa em placa, foi observada elevada celularidade, com células redondas, dispostas individuais e uniformemente pela lâmina, por vezes sobrepostas. Células com citoplasma moderado, levemente basofilico, núcleo excêntrico, com cromatina frouxa e nucléolos evidentes, por vezes múltiplos. Presença de células binucleadas a multinucleadas, e figuras de mitoses atípicas. Intenso pleomorfismo, com marcada anisocitose e anisocariose. Presença de células inflamatórias, em grande quantidade, principalmente neutrófilos, além de grande quantidade de hemácias (Figura 1).

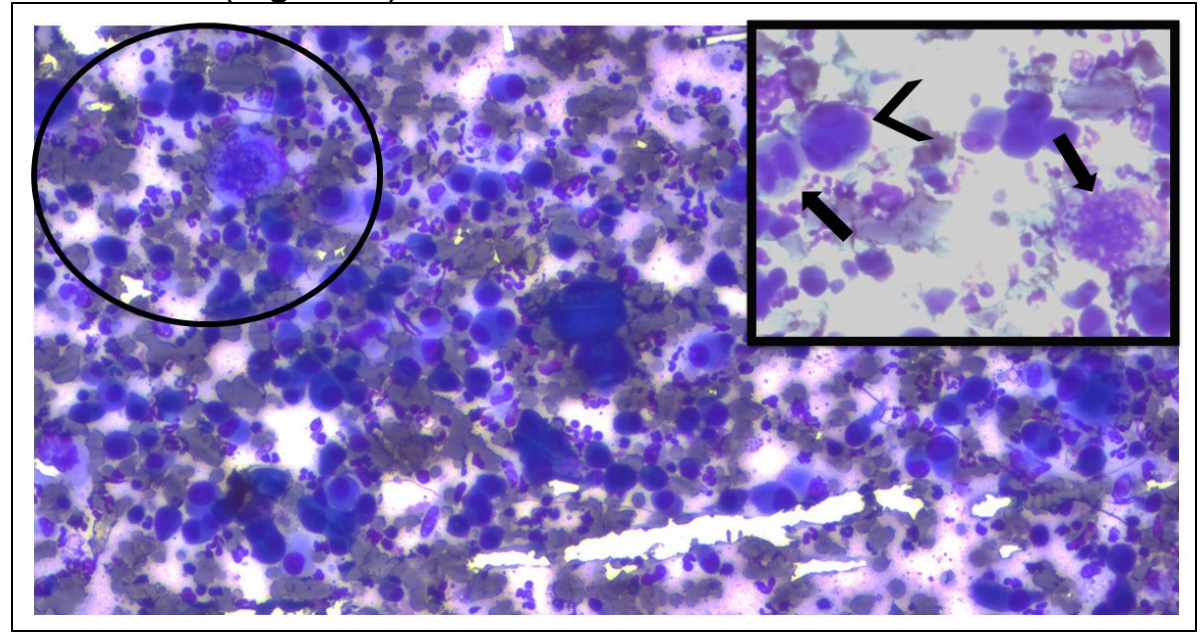

FIGURA 1- Coloração em Panótico rápidoß. Na imagem nota-se as células redondas neoplásicas com acentuado pleomorfismo celular. No destaque (círculo), observamos em maior aumento (canto superior direito), presença de figuras de mitose atípicas (setas) e um célula binucleada (cabeça de seta). Aumento de 100x e de 400x(destaque). Fonte: Laboratório de Patologia Animal UFU.

Os achados microscópicos da análise citológica são característicos de neoplasia maligna de células redondas. Dentre todas as neoplasias de células redondas, as características descritas no nódulo puncionado se assemelham mais a células de sarcoma histiocítico. Geralmente, nesse tipo de neoplasia são visualizadas células com acentuado pleomorfismo, e por vezes células gigantes multinucleadas. Uma característica que difere esse tipo dos outros tipos de proliferações histiocíticas, é a visualização de figuras de mitose atípicas (MEINKOTH et al, 2009).

Já na punção do nódulo em mama torácica cranial direita, foram observadas células arredondadas a ovaladas, dispostas em grupos. Citoplasma basofilico, núcleo central arredondado a ovalado, com cromatina frouxa e nucléolo evidente. Pleomorfismo acentuado, com marcada anisocitose e anisocariose. Presença de células inflamatórias polimorfonucleares, caracterizadas principalmente por neutrófilos.

O agrupamento de células de formato arredondado a ovalado, são características típicas de carcinomas. Sendo o nódulo localizado em região de mama, podendo se diagnosticar o nódulo na punção citológica como um carcinoma mamário. Os carcinomas mamários são neoplasias extremamente comuns nas cadelas, havendo também uma relação direta do aparecimento desse tumor com a castração desses animais, e com a idade em que este procedimento foi realizado (GOLDSHMIDT, 2017). 
Durante o exame necroscópico, foi visualizado no exame externo, o aumento de volume em placa na região das mamas que aumentara de tamanho e que se estendia de mama torácica caudal a mama inguinal esquerdas (Figura 2a). Ao corte da massa notou-se uma superfície irregular, de coloração variando entre esbranquiçada e rosada, de consistência macia (Figura $2 b$ ). O linfonodo inguinal ipsolateral também se encontrava aumentado de tamanho, de coloração enegrecida e formato irregular. Além disso, havia presença de aumento de volume em membro pélvico esquerdo, em terço médio de região caudal de coxa. Ao corte do aumento de volume, foi observada superfície multinodular e que fluía um líquido viscoso, e de coloração esverdeada.

Ao rebater pele, notou-se o linfonodo axilar esquerdo aumentado de tamanho, de superfície irregular, coloração esbranquiçada com áreas enegrecidas (Figura 2c). Ao corte esse possuía consistência macia, e fluía conteúdo viscoso e de coloração esverdeada. Não foram identificadas alterações macroscópicas nos órgãos que indicassem metástase.

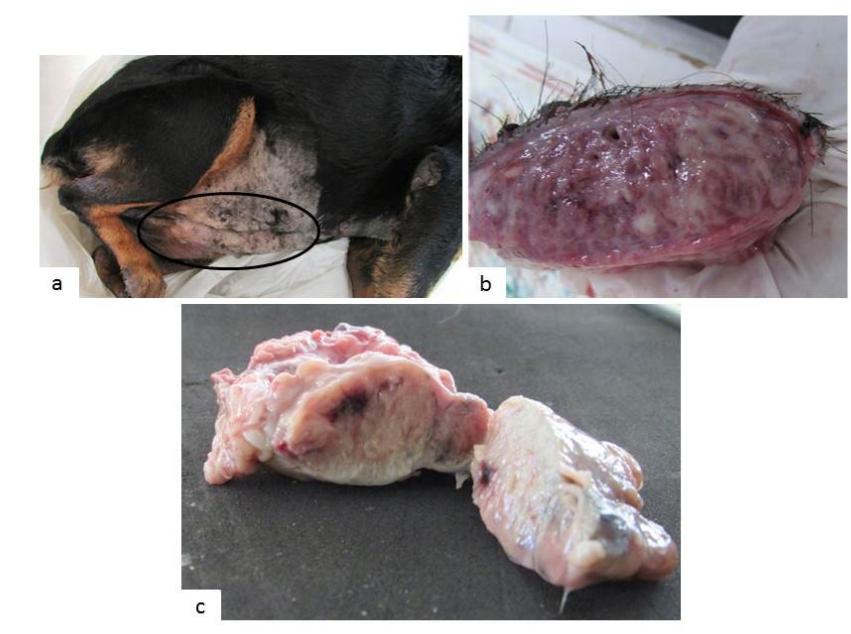

FIGURA 2- a. Animal em decúbito lateral esquerdo evidenciando o aumento de volume em região de cadeia mamária esquerda; b. Ao corte da cadeia mamária notou-se superfície irregular de coloração rosada com áreas esbranquiçadas; c. Corte de linfonodo axilar esquerdo, aumentado de tamanho, de formato irregular e coloração esbranquiçada. Fonte: Laboratório de Patologia Animal UFU.

Já a massa encontrada em parede dorsal de cavidade abdominal apresentava-se aderida e não possuía formato e contornos regulares, mostrando-se altamente invasiva na avaliação macroscópica (Figura 3). Ao corte da mesma, a coloração estava esbranquiçada, com áreas enegrecidas. Não foi observado envolvimento ósseo.

Segundo Affolter e Moore, 2002, os locais de acometimento dos sarcomas histiocíticos localizados e disseminados foram principalmente em subcutâneo e músculo esquelético, e baço, respectivamente. O sarcoma histiocítico localizado geralmente se mostra como um nódulo visível em pele, e que em casos metastáticos se dissemina principalmente para os linfonodos periféricos (AFFOLTER; MOORE, 2002; HENDRICK, 2017), como os descritos neste relato. Os linfonodos acometidos no caso foram o linfonodo inguinal e o linfonodo axilar ipsolateral à massa. 
A característica macroscópica desse tipo de tumor é bastante variável, podendo ser encontrado como nódulos únicos ou tumores em placas. A coloração varia dentre amarelada a esbranquiçada (HENDRICK,2017). O caso relatado é compatível com o descrito em literatura, já que o animal apresentou primariamente um aumento de volume em placa em região subcutânea de glândula mamária.

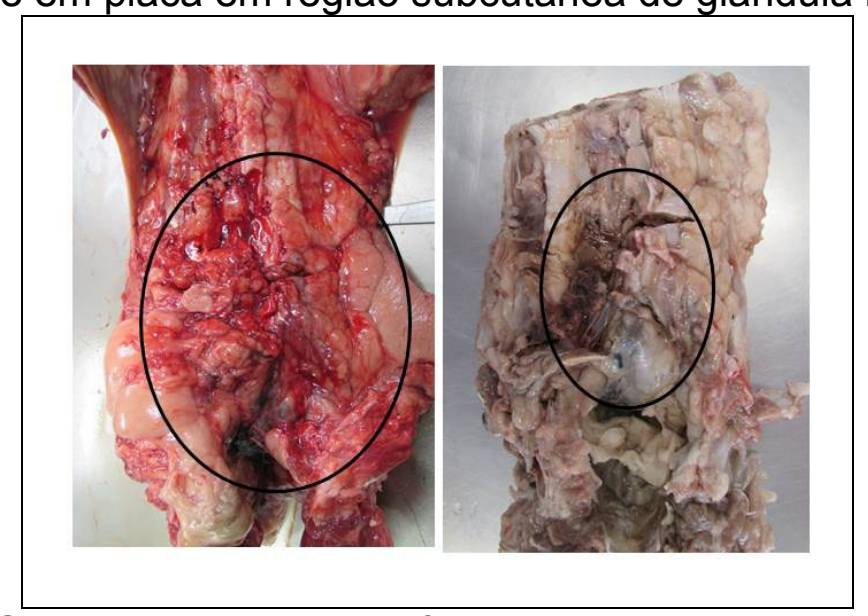

FIGURA 3- Em evidencia na figura (círculo preto), nota-se a massa aderida em região dorsal de parede de cavidade abdominal. A massa é irregular, sem delimitações visíveis, com consistência macia. À esquerda figura da massa encontrada no momento da necropsia, e à direita figura da mesma massa fixada em formol 10\%. Fonte: Laboratório de Patologia Animal UFU.

O sarcoma histiocítico localizado tem sido descrito mais frequentemente acometendo regiões subcutâneas de membros, e sua característica macroscópica pode variar entre nódulos e placas com áreas alopécicas (AFFOLTER; MOORE, 2002; HENDRICK, 2017). Devido à maior frequência do aparecimento do tumor em região de glândula mamária serem diagnosticados como neoplasmas mamários, principalmente em cadelas adultas a idosas (GOLDSHMIDT et al., 2017), a massa encontrada no cão do presente relato pode ter sido diagnosticada no exame citológico erroneamente como carcinoma mamário.

Apesar do aparecimento de tumores em região subcutânea, no caso apresentado acima houve o aparecimento de uma massa aderida à musculatura de região dorsal de parede da cavidade abdominal. A apresentação de um caso semelhante foi descrita também por Santos, et al, 2013, onde um cão da raça Pastor Alemão apresentava uma massa que acometia região dorsal da parede da cavidade torácica do animal. Além do relatado por Santos et al., (2013) não foram encontradas na literatura mais relatos de casos com descrição de sarcoma histiocítico em local semelhante do caso apresentado nesse trabalho, o que pode inferir a raridade do aparecimento dessa neoplasia nesse local.

$\mathrm{Na}$ análise microscópica de massa localizada em mama, foi observada uma proliferação de células neoplásicas, de formato variando de arredondado a poliédrico, de tamanho grande, com elevado pleomorfismo celular. O citoplasma dessas células se apresentava amplo, de coloração levemente eosinofílica, e o núcleo possuía formato reniforme a ovalado, em sua maior parte com cromatina frouxa, nucléolo evidente, sendo frequente a visualização de células com múltiplos núcleos. Essas células estavam arranjadas em manto e invadiam a região de ductos mamários, alterando assim a arquitetura da glândula (Figura 4). 


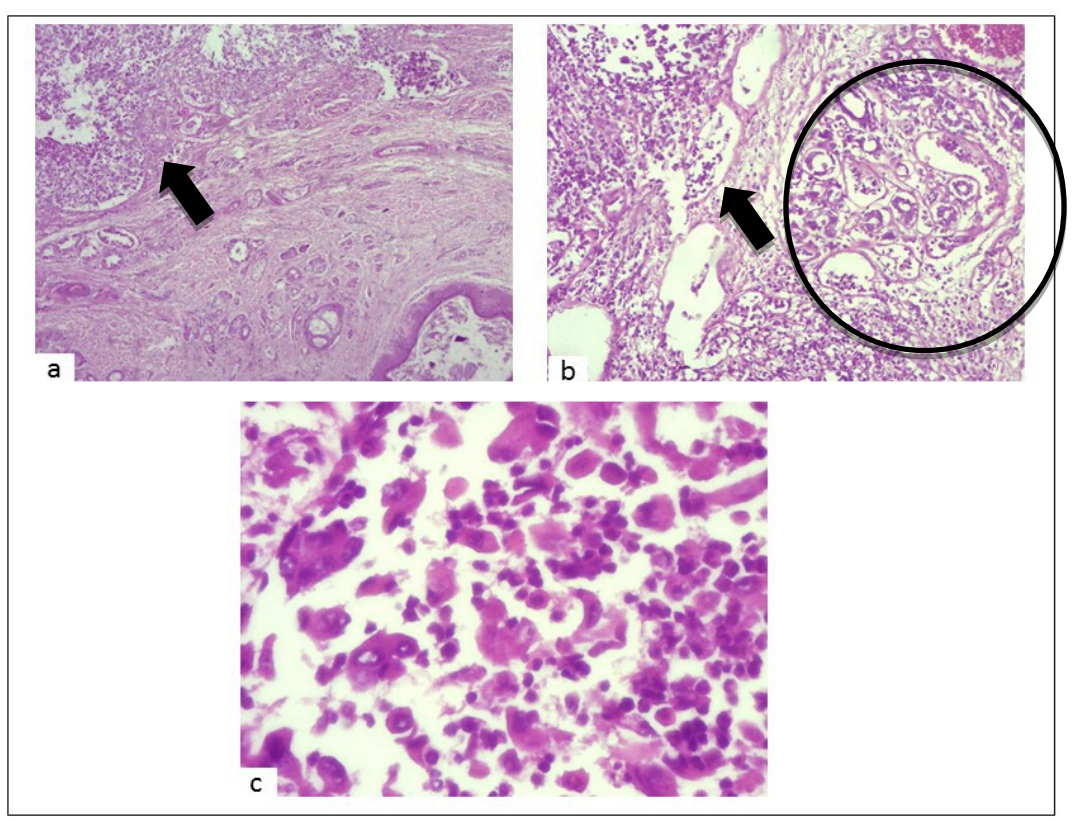

FIGURA 4- Coloração em H.E. a- Proliferação das células neoplásicas adentrando túbulos de glândula mamária (seta). Aumento de 40x. bNota-se células neoplásicas distribuídas em manto por entre túbulos de glândula mamário (seta), ao lado de túbulos ainda não atingidos pela neoplasia (círculo). Aumento de 100x. c- No destaque as células neoplásicas de formato variado, típicas de sarcoma histiocítico. Aumento de 400x. Fonte: Laboratório de Patologia Animal UFU.

Já na histopatologia dos linfonodos axilar e inguinal esquerdos, observaramse as mesmas células, acometendo principalmente a região cortical do órgão, porém já infiltrando para região medular. Nele notou-se a proliferação das células arredondadas, de formato grande, núcleo variando entre central e periférico, citoplasma amplo, eosinofílico, cromatina frouxa e nucléolo evidente. Notou-se também inúmeras células multinucleadas e gigantes (Figura 5).

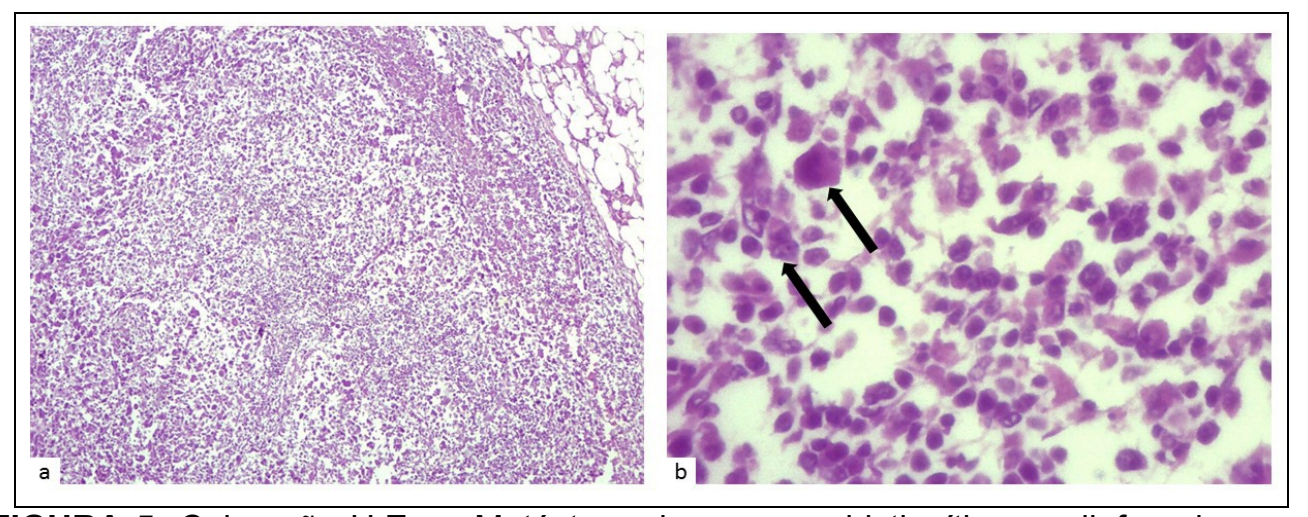

FIGURA 5- Coloração H.E. a- Metástase de sarcoma histiocítico em linfonodo com proliferação das células neoplásicas distribuídas em região cortical e medular, afetando a arquitetura do órgão. Aumento de 40x. b- Nota-se células neoplásicas de formato poliédrico (seta) de entremeio a população normal de linfonodo. Aumento de 400x. Fonte: Laboratório de Patologia Animal UFU.

Por fim a massa aderida à musculatura de região dorsal da cavidade abdominal apresentou na microscopia proliferação das mesmas células neoplásicas, arranjadas em manto, e distribuídas em derme e subcutâneo, por entre fibras musculares. 
Todos os resultados obtidos das análises microscópicas são compatíveis com neoplasia de células de sarcoma histiocítico. As células predominantes nesse tipo de tumor são grandes, arredondadas, com núcleo reiniforme, e citoplasma abundante e eosinofílico, compatível com as células descritas na análise microscópica do caso acima. Além disso, as células apresentam elevado pleomorfismo celular, podendo frequentemente apresentar células multinucleadas (HENDRICK, 2017).

O complexo sarcoma histiocítico é uma neoplasia não muito comum no cão, havendo estudos que mostram a frequência do sarcoma histiocítico como baixa em comparação com neoplasias malignas de pele e com neoplasias esplênicas malignas (HENDRICK, 2017; da SILVA et al, 2017). Há uma predisposição genética já estudada que explica o aparecimento dessa neoplasia principalmente em cães da raça Bernese Mountain, porém já foi relatado o aparecimento dessa neoplasia com uma frequência maior também em cães das raças Flat-coated Retriever, Golden Retriever, Pastor Alemão e Rottweiler (DOBSON, 2013; TAKADA et al, 2016). Apesar de essas raças apresentarem uma maior predisposição, comparado com as outras raças, ao desenvolvimento do complexo sarcoma histiocítico, não existem estudos que indiquem a frequência em que esse complexo acomete os cães da raça Rotweiler.

Quanto a idade em que esse tumor acomete os animais, foi encontrada uma variação entre dois e 13 anos de idade (AFFOLTER; MOORE, 2002). Portanto, o cão relatado se encaixa na faixa etária proposta. Não há relatos de predisposição de sexo para o acometimento desse tumor.

O tempo de sobrevida do animal a partir do diagnóstico de sarcoma histiocítico não possui dados relevantes, porém em estudo realizado por Dervisis et al., (2016), de 180 animais analisados, 10 vieram a óbito em sete dias. No caso descrito, o animal veio à óbito dois dias após o diagnóstico realizado pela punção aspirativa por agulha fina. Dentre os animais estudados por Dervisis et al, 2016, a média de sobrevida foi de 170 dias após o diagnóstico, e dentre os fatores que influenciavam essa média estava incluída a presença de metástase para linfonodo em sarcomas histiocíticos localizados, o que decrescia a sobrevida do animal, corroborando com os dados obtidos onde neste caso o animal apresentava metástase para mais de um linfonodo o que diminuiu drasticamente a sobrevida do animal.

\section{CONCLUSÃO}

A neoplasia relatada no caso acima se tratou de um sarcoma histiocítico, com diagnóstico confirmado por exames citopatológico e histopatológico. As características macroscópicas da lesão se assemelham a inúmeras outras neoplasias, como a exemplo o carcinoma mamário inflamatório, o que pode levar a um erro em um diagnóstico apenas clínico.

Portando, o caso nos atenta a não descartar essa neoplasia maligna altamente agressiva independentemente da localização, aparência e distribuição incomuns, proporcionando um diagnóstico mais preciso e consequentemente uma melhor escolha de tratamento para o paciente.

\section{REFERÊNCIAS}

AFFOLTER, V. K.; MOORE, P. F. Localized and Disseminated Histiocytic Sarcoma of Dendritic Cell Origin in Dogs. Veterinary Pathology, v. 39, p. 74-83, 2002. Disponível em: <doi/abs/10.1354/vp.39-1-74>. doi: 10.1354/vp.39-1-74 
CANNON, C.; BORGATTI, A.; HENSON, A.; HUSBANDS, B. Evaluation of a combination chemotherapy protocol including lomustine and doxorubicin in canine histiocytic sarcoma. Journal of Small Animal Practice, v. 56, Issue 7, p. 425 - 429, 2015. Disponível em: <https://doi.org/10.1111/jsap.12354>. doi: 10.1111/jsap.12354

DERVISIS, N. G.; KIUPEL, M.; QIN, Q.; CESARIO, L. Clinical prognostic factors in canine histiocytic sarcoma. Veterinary and Comparative Oncology, v. 15, Issue 4, p. 1171-1180, 2017. Disponível em: <https://doi.org/10.1111/vco.12252>. doi: $10.1111 /$ vco. 12252

DOBSON, J. M. Breed-Predispositions to Cancer in Pedigree Dogs. ISRN Veterinary Science, 2013. Disponível em: http://dx.doi.org/10.1155/2013/941275>. doi: 10.1155/2013/941275

GOLDSHMIDT, M. H.; PEÑA, L.; ZAPPULLI, V. Tumors of the Mammary Gland. In: D. J. Meuten (Ed.), Tumors in Domestic Animals, (5 th edit.), lowa State Press, Ames (2017), pp. 723-765.

HEDAN, B.; THOMAS, R.; MOTSINGER-REIF, A.; ABADIE, J.; ANDRE, C.; CULLEN, J.; BREEN, M. Molecular cytogenetic characterization of canine histiocytic sarcoma: A spontaneous model for human histiocytic cancer identifies deletion of tumor suppressor genes and highlights influence of genetic background on tumor behavior. BMC Cancer, v. 11. 2011. Disponível em: < https://doi.org/10.1186/14712407-11-201>. doi: 10.1186/1471-2407-11-201

HENDRICK, M. J. Mesenchymal Tumors of the Skin and Soft Tissues. In: D. J. Meuten (Ed.), Tumors in Domestic Animals, (5 th edit.), lowa State Press, Ames (2017), pp. 142-175.

MARIANI, C. L.; JENNINGS, M. K.; OLBY, N. J.; BORST, L. B.; BROWN JR, J. C.; ROBERTSON, I. D.; SEILER, G. S.; MACKILLOP, E. Histiocytic Sarcoma with Central Nervous System Involvement in Dogs: 19 Cases (2006 - 2012). Journal of Veterinary Internal Medicine, v. 29, Issue 2, p. 607 - 613, 2015. Disponível em: <https://doi.org/10.1111/jvim.12554>. doi: 0.1111/jvim.12554

MEINKOTH, J. H.; COWELL, R. L.; TYLER, R. D. Tipos Celulares e Critérios de Malignidade. In: R. L. Cowell; R. D. Tyler; J. H. Meinkoth; D. B. DeNicola (Ed.), Diagnóstico Citológico e Hematologia de Cães e Gatos, (3ª ed), MedVet (2009), p. 20-46.

MOORE, P. F.; AFFOLTER, V. K.; VERNAU, W. Canine Hemophagocytic Histiocytic Sarcoma: A Proliferative Disorder of CD11d+ Macrophages. Veterinary Pathology, v. 43, Issue 5, p. $632-645,2006$.

MOORE, P. F. A Review of Histiocytic Diseases of Dogs and Cats. Veterinary Pathology, v 51, Issue 1, p. 167-184, 2014. Disponível em: <http://journals.sagepub.com/doi/pdf/10.1177/0300985813510413>. Doi: $10.1177 / 0300985813510413$ 
MOORE, P. F.; Canine and Feline Histiocytic Diseases. In: D. J. Meuten (Ed.), Tumors in Domestic Animals, (5 ${ }^{\text {th }}$ edit), lowa State Press, Ames (2017), pp. $322-$ 336.

SANTOS, I. F. C.; CARDOSO, J. M. M.; SHIAN, C.; MARUJO, R. B.; SILVA, L. F. Sarcoma Histiocítico em Cão: Relato de Caso. Veterinária e Zootecnia, v. 20, p. 576-581; 2013. Disponível em: <189.126.110.61/rvz/article/download/19892/2073>. doi: 189.126.110.61

SILVA da, E. O.; CIPRIANO, I. A.; PEREIRA, L. G.; GOIOZO, P. F. I.; Diagnóstico histopatológico de dermatopatias em cães: Estudo retrospectivo (2005 - 2015). Colloquium Agrariae, v. 13, n. 13, p. 115-121, 2017. Disponível em: < http://revistas.unoeste.br/revistas/ojs/index.php/ca/article/viewFile/1740/1997>. doi: 10.5747/ca.2017.v13.n3.a180

TAKADA, M; PARYS, M; GREGORY-BRYSON, E.; SAAVEDRA, P. V.; KIUPEL, M. YUSBASIYAN-GURKAN, V. A novel canine histicyitic sarcoma cell line: initial characterization and utilization for drug screening studies. BMC Cancer, v. 18, 2018. Disponível em: < https://doi.org/10.1186/s12885-018-4132-0>. Doi: 10.1186/s12885018-4132-0 